\title{
Is body mass index (BMI) or body adiposity index (BAI) a better indicator to estimate body fat and selected cardiometabolic risk factors in adults with intellectual disabilities?
}

\author{
Anna Zwierzchowska', Diana Celebańska ${ }^{1 *} \mathbb{0}$, Barbara Rosołek¹, Krystyna Gawlik² and Aleksandra Żebrowska
}

\begin{abstract}
Background: The BMI index cannot always be used in people with intellectual disabilities due to neuromuscular coordination disorders and psychological barriers that may hinder conventional body weight measurement. The study aimed to assess the usefulness of BMI and BAI in estimating obesity and body fat in people with intellectual disabilities.

Methods: The first stage of the research involved 161 people with profound intellectual disabilities. Somatic parameters (BM, BH, WC, HC) were measured and BMI, BAI, WHR were calculated. Fifty seven persons with above-normal BMI and BAI were included in the second stage of the study and biochemical parameters were determined (TC, LDL-cholesterol, HDL-cholesterol, TG, GL).

Results: According to both BMI and BAl classifications, most people were overweight or obese. A high correlation of \%BF with BMI and BAl indices was observed $(r=0.78)$. The sensitivity of both indices was $95.65 \%$. In groups with above-normal BMI and BAl, an upward trend was found for mean values of TC, LDL, TG, and GL, with a simultaneous downward trend for HDL. Statistically significant intergroup differences were recorded for TG and $G L(p<0.05)$ for both indices (BMI and BAI).

Conclusions: Our research demonstrated that BAI is complementary to BMI and can be recommended for the estimation of body fat and cardiometabolic risks in people with intellectual disabilities. Due to the ease of measurement, BAI has high utility value.
\end{abstract}

Keywords: Intellectual disabilities, Body mass index, Body adiposity index, Cardiometabolic risk

\section{Background}

Excess body fat (\%BF) is a marker of obesity viewed as a chronic and complex metabolic disease that is one of the main risk factors for cardiometabolic diseases, disabilities, and deaths $[1,2]$. A reliable and unquestioned estimation of \%BF in the human body requires

*Correspondence: d.celebanska@awf.katowice.pl

${ }^{1}$ Institute of Sport Sciences, The Jerzy Kukuczka Academy of Physical Education in Katowice, ul. Mikołowska 72a, 40-065 Katowice, Poland Full list of author information is available at the end of the article expensive diagnostics in the form of a dual-energy $\mathrm{X}$-ray absorptiometry (DEXA). However, in clinical practice, it is most often conducted in laboratory conditions, thus not being widely used in epidemiological studies. In population studies, body fat is mostly estimated using electrical bioimpedance analysis (BIA), which shows a high correlation with DEXA [3-5]. Despite the increased availability of tools for \%BF measurement, professional equipment is not widespread in society, whereas publicly available household scales with body fat analyzers are characterized by 
large measurement errors [6]. One alternative to complex devices are indices computed based on anthropometric characteristics, which allow for easy and non-invasive estimation of body fat, providing indirect and quick information about the person's health status.

Body mass index (BMI), considered the obesity index, is a widely used index recommended by WHO for social use, but it is also used in scientific research [7-9]. It defines body weight to height ratio but does not differentiate between muscle and fat mass and its distribution. BMI does not take into account the effect of age, sex, and race, which largely determine the amount of body fat [9-12].

The last decade has seen the verification of the body adiposity index (BAI) developed by Bergman et al. [11]. It has been shown that BAI takes into account both age and sex [13], can be used in both Caucasian and Mediterranean populations [12,14], and is a sensitive tool in estimating obesity among people with forced sedentary lifestyles [15]. Similarly, the significant sensitivity of the tool was indicated by Godoy-Matos et al. [16] who examined extremely obese women (BAI was more correlated with \%BF than BMI). In conclusion, the results of the research to date, although not always unequivocal, reveal both methodological and interpretative limitations of BAI. However, they indicate significantly higher sensitivity of BAI in estimating body fat in obese people than its specificity in population studies.

There are no studies available in the literature on the subject to date that have analyzed indices of obesity and body fat in people with severe intellectual disabilities, $[17,18]$. All the more so, the verification of the index in the population of people with intellectual disabilities is important because the measurement of body mass of these people may be flawed due to neuromuscular control disorders and psychological barriers, which lead to problems with the correct load to the tool for measurement of body mass and body composition $[19,20]$. At the same time, it has been shown that a severe intellectual disability determines body structure and body fat distribution, which justifies the need to verify the indices of obesity and body fat in the general population [21]. The study aimed to assess the usefulness of the indices of obesity (BMI) and body fat (BAI) in a group of people with intellectual disabilities. It was assumed that BAI is characterized by a higher correlation with body fat (\%BF) than BMI and that it is more sensitive in estimating obesity than BMI. Furthermore, based on BMI and BAI, an attempt was made to identify selected cardiometabolic risk factors.

\section{Materials and methods}

The research was conducted in two stages (Fig. 1), using direct observation, whereas the selection of the respondents was purposive. In the first stage, the inclusion criteria were adopted, i.e. age over 18 years, severe intellectual disability [22], and participation in occupational therapy classes. The aetiology of intellectual disabilities was identified based on health records. It was found that in the case of $75 \%$ of the participants, the aetiology was of constitutional origin of the prenatal period, including numerical, sexual and structural chromosomal aberrations (45\%). Next, the aetiology related to the diseases suffered by mothers during pregnancy should be indicated (30\%), with the focus on exogenous factors, toxic substances, and medicines. The perinatal period, i.e. intrauterine hypoxia, cerebral palsy, improper surgical interventions was associated with $20 \%$ cases. The remaining $5 \%$ were not classified.

As a result, 161 people (72 women and 89 men) were qualified for the first stage. The following somatic features were measured: body weight (BM), body height (BH), waist circumference (WC), and hip circumference (HC). WC and $\mathrm{HC}$ were measured according to the WHO (2011) methodology, whereas \%BF was measured using a Tanita MC-780 MA analyzer (Table 1).

BMI (related to WHO norms [23]), waist to hip ratio (WHR) (related to WHO norms [24]) and BAI (related to cutoffs as proposed by Bergman et al. [11]) were calculated. The following formula was used for the computation of BAI [11]:

$$
\text { BAI }=\frac{\text { hip in } \mathrm{cm}}{\text { height in } \mathrm{m}}-18
$$

In the second stage of the study, persons who did not express the consent for blood sampling were excluded from the study. As a result, the lipid profile (total cholesterol (TC), LDL-cholesterol, HDL-cholesterol, and triglycerides (TG)) and glucose (GL) concentration were evaluated in 57 people with intellectual disabilities. The blood samples were obtained on an empty stomach in the morning (the participants were examined at least $12 \mathrm{~h}$ after their last meal). The determination of biochemical parameters was carried out with the use of Randox diagnostic tests in the analytical laboratory of the Jerzy Kukuczka Academy of Physical Education in Katowice.

The research was part of the project "Lifestyles and the threat of the diseases of affluence in adults with disabilities" conducted by the Department of Physical Education and Adapted Physical Activity of the Jerzy Kukuczka Academy of Physical Education in Katowice.

The research project received a positive opinion of the Bioethics Committee of the Academy of Physical 


\section{STAGE 1}

Obtaining the consent of the bioethics committee, participants and caregivers. Purposive sampling according to the adopted inclusion criteria $(\mathrm{n}=161)$

Age min-max 21-55; $\bar{x}=32 ; \mathrm{sd} .=7.4$

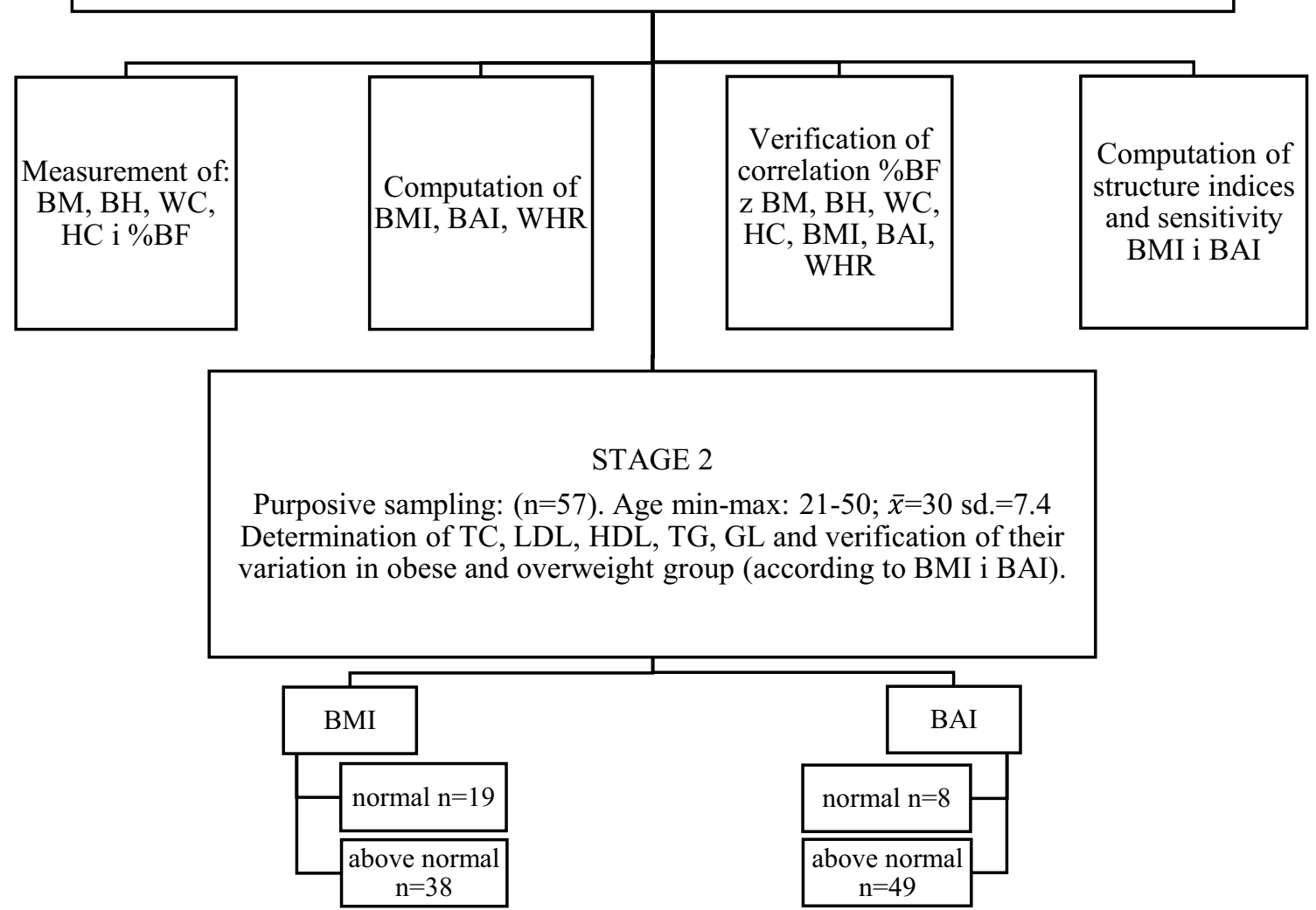

Fig. 1 Research methodology

Table 1 Somatic characteristics of the female and male participants

\begin{tabular}{lcc}
\hline Sex & Female $(\mathbf{n}=\mathbf{7 2}) \bar{x} \mathbf{s d}$ & Male $(\mathbf{n}=\mathbf{8 9}) \bar{x} \mathbf{\pm} \mathbf{d}$ \\
\hline Age (years) & $32.1 \pm 8.79$ & $32.0 \pm 6.11$ \\
BH (cm) & $155.8 \pm 8.93$ & $171.6 \pm 9.48$ \\
BM (kg) & $66.0 \pm 18.70$ & $77 \pm 18.55$ \\
Waist circumference & $86.2 \pm 16.5$ & $92.2 \pm 14.7$ \\
$\quad(\mathrm{~cm})$ & & $102.1 \pm 12.6$ \\
Hip circumference $(\mathrm{cm})$ & $103.5 \pm 12.6$ & \\
\hline
\end{tabular}

Education in Katowice (Resolution of 8 March 2012 No. 9/2012). The study protocol conforms to the ethical guidelines of the 1975 Declaration of Helsinki as reflected in a priori approval by the institution's human research committee. The subjects were informed about the purpose and procedure of the study, expressed their written informed consent for the participation, and were allowed to withdraw from the participation at any stage of the study. Written consents for the incapacitated individuals were obtained from legal guardians. The data obtained in the research were secured in accordance with the Personal Data Protection Act of 10 May 2018 (Journal of Laws of 2018, item 1000).

\section{Statistical analysis}

The normality of distribution was evaluated for age and somatic features (BM, BH, WC, $\mathrm{HC}$ ), indices (BMI, BAI, WHR, \%BF), and parameters (TC, HDL, LDL, GL, TG) (Kolmogorov-Smirnov test) $(\mathrm{n}=161)$. The correlation of \%BF with features and indices (Spearman's rank correlation) was verified. The most correlating indices were selected for further analysis (BMI, BAI). In accordance with the norms (BMI) (group with normal values $(18.5<\mathrm{BMI}<24.9)$ and excess body mass of $(\mathrm{BMI} \geq 25.0))$ and cutoffs (BAI) (cutoffs by age and gender rates for women $>35 \%$ and for men $>22 \%$ ), the subjects were 
divided into groups and, based on them, the significance of differences between the structure indices for groups was calculated and verified.

The sensitivity of BMI and BAI was verified relative to $\% B F$. The statistical significance of differentiation of mean values of biochemical parameters (GL, TC, HDL, LDL, TG) between groups of patients with normal and abovenormal BMI and BAI cutoff points (U test) $(n=57)$ was verified. The statistical significance of differences was set at $p<0.05$.

\section{Results}

The presence of correlations between \%BF and somatic features was verified and the strongest statistically significant correlation was found between $\% \mathrm{BF}$ and BMI and between \%BF and BAI (Table 2). Therefore, further analysis was conducted based on these two indices.

After the classification of the participants according to norms and BAI cutoff points for women and men, it was shown that the vast majority of them were obese or overweight, regardless of the classification criterion (BMI/ $\mathrm{BAI})$. The calculated structure index revealed statistically significant differences between groups (BMI $n=90$; $55.9 \%$ and BAI $\mathrm{n}=126 ; 78.3 \% p<0.01$ ). Furthermore, assuming the $\% \mathrm{BF}$ as a golden standard, the sensitivity of BMI and BAI indices was verified and it amounted to 95.65\% for both indicators (Fig. 2).

In the second stage, mean values of biochemical parameters were compared in groups classified according to BMI norms and BAI cutoff points (Table 3 ). The expected upward trend of mean values of TC, LDL, TG, GL was observed, with a simultaneous downward trend for HDL both in the group with above-normal BMI and in the group with BAI above cut-off points. Statistically significant intergroup differences were recorded for TG and GL $(p<0.05)$ for both indices (BMI and BAI) (Table 3).

\section{Discussion}

Obesity has been identified in a substantial part of the population of people with intellectual disabilities, leading to increased cardiometabolic risks [25]. This leads to the search for reliable, cheap, and easy to use tools to estimate obesity and body fat in this group of disabilities. It has been shown that \%BF measured using the bioimpedance method has a high correlation with BMI, i.e. the index for estimating obesity that is most frequently recommended for the general population [14, 26, 27]. These findings were consistent with our results as both BMI and BAI, also verified using the bioimpedance (BIA) method, showed a statistically significant correlation (between BMI and \%BF $(\mathrm{r}=0.78)$ and between BAI and $\% \mathrm{BF}(\mathrm{r}=0.78) p<0.01)$. The results obtained suggest that both BMI and BAI may be a recommended tool for estimation of excess weight of patients with intellectual disabilities.

It should be emphasized that few studies have assessed the use of BMI in the population of people with intellectual disabilities and often involved groups that differ in terms of the aetiology, age, comorbid conditions, ways of interpreting the data (growth charts or norms for estimation of obesity). Consequently, the results of these studies are ambiguous in terms of the validity of the use of BMI in this group of people with disabilities $[4,18,28]$. The BAI index, which has been popular in recent years in estimating body fat, is gaining increasing interest. The authors of the index point to significant links between BAI and the estimation of cardiometabolic disease risk, which increases its potential for the interpretation of body fat [11]. However, the results of the research conducted to date in populations of different ethnicity, age, gender, disability, and metabolic disease syndromes, are varied, without finally confirming its diagnostic importance [12, 14-16, 29-31].

However, studies to date on the BAI index among people with intellectual disabilities indicate its tendency to overestimate body fat $[18,32,33]$, which would suggest its low specificity for this population. Our findings are consistent with this thesis because the sensitivity of the test for the analyzed group for both $\mathrm{BAI}$ relative to $\% \mathrm{BF}$ and $\mathrm{BMI}$ relative to \% $\mathrm{BF}$ was at the level of $95 \%$, although the group structure based on the BAI cutoff point and BMI norms was significantly different $(p<0.01)$. Only a detailed analysis of the second stage of the study demonstrated that people classified outside the BAI cutoff points often remained in the normal range according to BMI classification. As expected, the values of biochemical parameters were higher both in the group of people with above-normal BMI and people with BAI above cutoff points. Furthermore, it was observed that the values

Table 2 Relationship of somatic features and indices relative to body fat

\begin{tabular}{cccccccc}
\hline & BM & BH & WC & HC & BMI & BAI & WHR \\
\hline \%BF & & & & & & & \\
$r$ & 0.53 & -0.26 & 0.63 & 0.77 & 0.78 & 0.78 & 0.25 \\
$p$ & 0.001 & 0.001 & 0.001 & 0.001 & 0.001 & 0.001 & 0.001 \\
\hline
\end{tabular}




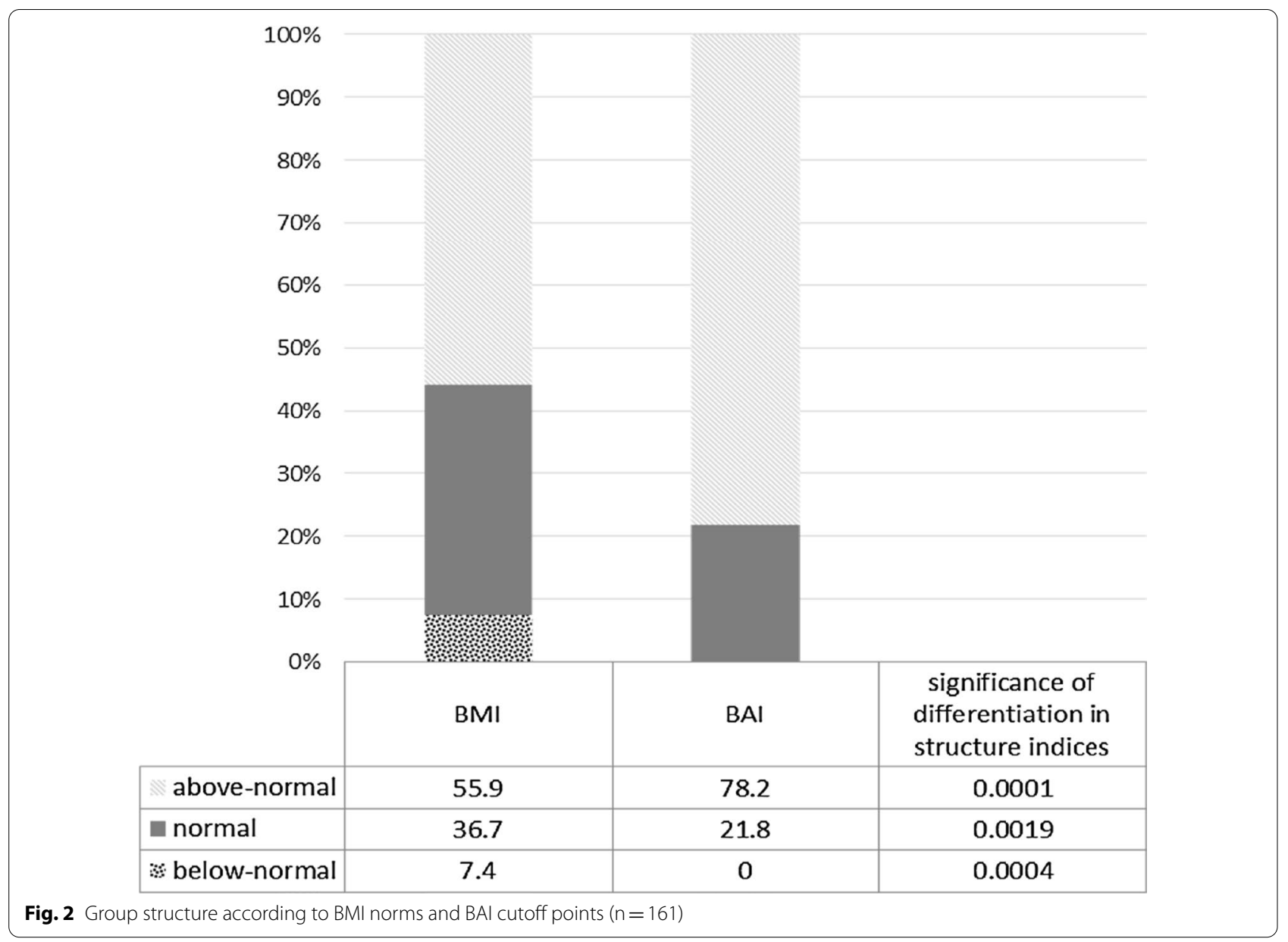

Table 3 Mean values of biochemical parameters according to BMI norms and BAI cutoff points

\begin{tabular}{|c|c|c|c|c|c|c|}
\hline & \multicolumn{3}{|l|}{ BMI } & \multicolumn{3}{|l|}{ BAI } \\
\hline & $\begin{array}{l}\text { Normal } \\
n=19\end{array}$ & $\begin{array}{l}\text { Above-normal } \\
n=38\end{array}$ & $p$ value & $\begin{array}{l}\text { Normal } \\
n=8\end{array}$ & $\begin{array}{l}\text { Above-normal } \\
n=49\end{array}$ & $p$ value \\
\hline TC (mg/dl) & $156.2 \pm 28.9$ & $172.9 \pm 35.8$ & - & $154.6 \pm 29.6$ & $169.4 \pm 34.9$ & - \\
\hline $\mathrm{HDL}(\mathrm{mg} / \mathrm{dl})$ & $65.1 \pm 18.8$ & $58.9 \pm 20.6$ & - & $70.7 \pm 22.1$ & $59.3 \pm 19.5$ & - \\
\hline LDL (mg/dl) & $76.1 \pm 28.0$ & $88.8 \pm 32.0$ & - & $70.2 \pm 28.8$ & $86.9 \pm 31.1$ & - \\
\hline TG (mg/dl) & $75.0 \pm 26.3$ & $128.8 \pm 70.2$ & 0.0004 & $68.0 \pm 16.9$ & $117.9 \pm 66.5$ & 0.0085 \\
\hline $\mathrm{GL}(\mathrm{mg} / \mathrm{dl})$ & $84.0 \pm 7.5$ & $92.1 \pm 15.8$ & 0.0486 & $82.7 \pm 5.7$ & $90.5 \pm 14.7$ & 0.0429 \\
\hline
\end{tabular}

of biochemical parameters of lipid profile indicated obesity and cardiometabolic risks, revealing statistically significant intragroup differentiation. Both in the group analyzed according to BMI norm and BAI cutoff points, there were statistically significant differences for TG and GL [BMI ( TG $=75.0 \pm 26.3 / 128.8 \pm 70.2)$ and $\quad(\mathrm{GL}=84.0 \pm 7.5 / 92.1 \pm 15.8)] ; \quad[\mathrm{BAI}$ $(\mathrm{TG}=68.0 \pm 16.9 / 117.9 \pm 66.5)$
$(\mathrm{GL}=82.7 \pm 5.7 / 90.5 \pm 14.7)]$ at $p<0.01$. No statistically significant differences for other biochemical parameters (HDL and LDL) were demonstrated, which suggests that both BMI and BAI are sensitive in estimating cardiometabolic risk only for TG and GL. Our results are consistent with the theses presented by Lizak et al. [13], Zwierzchowska et al. [15] concerning higher sensitivity and low specificity of BAI in 
estimating cardiometabolic risks in groups of people with intellectual disabilities.

\section{Strengths and weaknesses of the study}

In conclusion, the small number of studies on this problem and, consequently, the lack of comparability with our research is a limitation and weakness of this study. However, the fact that similar sensitivity of BAI and BMI was demonstrated unequivocally and that BAI index differentiates the group in terms of biochemical parameters identifying cardiometabolic syndrome allows for the recommendation of BAI as complementary to the BMI index. At the same time, it should be noted that only anthropometric features related to the length and width (BH and $\mathrm{WC}$ ) are taken into account in estimating BAI, which can sometimes make it easier to use. It seems that our results provide the answer to the study by Jaffrin [6], who indicated a measurement error in body weight and composition. This situation may be associated with frequent neuromuscular control disorders and psychological problems of people with intellectual disabilities, and, consequently, with an accurate estimation of BMI.

We observed a strength of the present study in this respect because we showed a prognostic value of BAI similar to BMI and its utilitarian potential, which can lead to the optimization of diagnostics for people with intellectual disabilities.

\section{Conclusions}

1. The BAI index shows good sensitivity but low specificity for estimating body fat among adults with intellectual disabilities. Furthermore, the BAI index is recommended as complementary to BMI in the prediction of cardiometabolic disease risks.

2. The BAI index has a high utility value due to the ease of collecting data used to calculate it, which is particularly important in the case of comorbid intellectual and motor disabilities (difficulty in maintaining a habitual body posture).

\begin{abstract}
Abbreviations
TC: Total cholesterol; LDL-cholesterol: Low density lipoprotein; HDL-cholesterol: High density lipoprotein; TG: Triglycerides; GL: Glucose; BMI: Body mass index; BAI: Body adiposity index; WHR: Waist hip ratio; WC: Waist circumference; BM: Body weight; $\mathrm{BH}$ : Body height; $\mathrm{HC}$ : Hip circumference; \%BF: Body fat percentage; WHO: World Health Organization; DEXA: Dual-energy X-ray absorptiometry.
\end{abstract}

Acknowledgements

Not applicable.

\section{Authors' contributions}

AZ was responsible for conceptualization, methodology, writing-original draft preparation, writing-review and editing and supervision. She contributed to funding acquisition. DC was responsible for conceptualization, methodology, data curation, writing-original draft preparation, visualization, updating reference lists and project administration. She conducted investigation. BR was responsible for conceptualization, methodology and data curation. She conducted data analysis. KG was responsible for writing-review and editing and supervision. She conducted investigation. AŻ was responsible for conceptualization and supervision. All authors read and approved the final manuscript.

\section{Funding}

This research was funded, as part of statut research from public funds, by The Jerzy Kukuczka Academy of Physical Education in Katowice, Grant No. AWF/

INS/ZB2/2020 (data collection and statistical analysis).

\section{Availability of data and materials}

The datasets used and/or analysed during the current study are available from the corresponding author on reasonable request.

\section{Declarations}

\section{Ethics approval and consent to participate}

The research project received a positive opinion of the Bioethics Committee of the Academy of Physical Education in Katowice (Resolution of 8 March 2012 No. 9/2012). The subjects were informed about the purpose and procedure of the study, expressed their written informed consent for the participation, and were allowed to withdraw from the participation at any stage of the study.

\section{Consent for publication}

All authors consented to the publication.

\section{Competing interests}

The authors declare no competing financial interests.

\section{Author details}

${ }^{1}$ Institute of Sport Sciences, The Jerzy Kukuczka Academy of Physical Education in Katowice, ul. Mikołowska 72a, 40-065 Katowice, Poland. ${ }^{2}$ Physiotherapy Department, The Pope John Paul II State School of Higher Education in Biala Podlaska, Sidorska 95/97, 21-500 Biała Podlaska, Poland.

Received: 4 August 2020 Accepted: 23 February 2021

Published online: 02 March 2021

\section{References}

1. YumukV, Tsigos C, Fried M, Schindler K, Busetto L, Micic D, Toplak H. Obesity Management Task Force of the European Association for the Study of Obesity. European Guidelines for Obesity Management in Adults. Obes Fact. 2015;8(6):402-24. https://doi.org/10.1159/000442721.

2. Bennasar-Veny M, Lopez-Gonzalez AA, Tauler P, Cespedes ML, VicenteHerrero T, Yañez A, et al. Body adiposity index and cardiovascular health risk factors in Caucasians: a comparison with the body mass index and others. PLoS ONE. 2013;8(5):e63999. https://doi.org/10.1371/journ al.pone.0063999.

3. Erselcan T, Candan F, Saruhan S, Ayca T. Comparison of body composition analysis methods in clinical routine. Ann Nutr Metab. 2000;44(5-6):243-8. https://doi.org/10.1159/000046691.

4. Esco MR, Nickerson BS, Bicard SC, Russell AR, Bishop PA. Agreement of BMI-based equations and DXA in determining body-fat percentage in adults with down syndrome. Adapt Phys Activ Q. 2016;33(1):89-96. https ://doi.org/10.1123/APAQ.2014-0240.

5. Chen KT, Chen YY, Wang CW, Chuang CL, Chiang LM, Lai CL, et al. Comparison of standing posture bioelectrical impedance analysis with DXA for body composition in a large, healthy Chinese population. PLOS ONE. 2016;11(7):e0160105. https://doi.org/10.1371/journal.pone.0160105.

6. Jaffrin MY. Body composition determination by bioimpedance: an update. Curr Opin Clin Nutr Metab Care. 2009;12(5):482-6. https://doi. org/10.1097/MCO.0b013e32832da22c. 
7. Lichtash CT, Cui J, Guo X, Chen YD, Hsueh WA, Rotter Jl, et al. Body adiposity index versus body mass index and other anthropometric traits as correlates of cardiometabolic risk factors. PLoS ONE. 2013;8(6):e65954. https://doi.org/10.1371/journal.pone.0065954.

8. Ortega FB, Sui X, Lavie CJ, Blair SN. Body Mass Index, the most widely used but also widely criticized index: would a criterion standard measure of total body fat be a better predictor of cardiovascular disease mortality? Mayo Clin Proc. 2016;91(4):443-55. https://doi.org/10.1016/j.mayoc p.2016.01.008.

9. Maffetone PB, Laursen PB. Revisiting the global overfat pandemic. Front Public Health. 2020;8:51. https://doi.org/10.3389/fpubh.2020.00051.

10. Jackson AS, Stanforth PR, Gagnon J, Rankinen T, Leon AS, Rao DC, et al. The effect of sex, age and race on estimating percentage body fat from body mass index: the Heritage Family Study. Int J Obes Relat Metab Disord. 2002;26(6):789-96. https://doi.org/10.1038/sj.ijo.0802006.

11. Bergman RN, Stefanovski D, Buchanan TA, Sumner AE, Reynolds JC, Sebring NG, et al. A better index of body adiposity. Obesity (Silver Spring). 2011;19(5):1083-9. https://doi.org/10.1038/oby.2011.38.

12. Zwierzchowska A, Grabara M, Palica D, Zając A. BMI and BAl as markers of obesity in a Caucasian population. Obes Facts. 2013;6(6):507-11. https:// doi.org/10.1159/000356402.

13. Lizak D, Budzowski A, Seń M, Czarny W. Anthropometric measures of body composition used in obesity diagnosis—an overview. Hygeia Public Health. 2016:51(2):124-33.

14. López AA, Cespedes ML, Vicente T, et al. Body adiposity index utilization in a Spanish Mediterranean population: comparison with the body mass index. PLoS ONE. 2012;7(4):e35281. https://doi.org/10.1371/journ al.pone.0035281.

15. Zwierzchowska A, Głowacz M, Maszczyk A, Zając A. Body adiposity index a better marker of body fat than body mass index in wheelchair rugby players after cervical spinal cord injury (CSCl) — preliminary investigations. Integr Obes Diabetes. 2015;1(5):112-6. https://doi.org/10.15761/ IOD.1000126.

16. Godoy-Matos AF, Moreira RO, Valerio CM, Mory PB, Moises RS. A new method for body fat evaluation, body adiposity index, is useful in women with familial partial lipodystrophy [published correction appears in Obesity (Silver Spring). 2012 May;20(5):1129]. Obesity (Silver Spring). 2012;20(2):440-3. https://doi.org/10.1038/oby.2011.343

17. Ramos-Jiménez A, Hernández-Torres RP, Wall-Medrano A, VillalobosMolina R. Metabolomic (anthropometric and biochemical) indexes and metabolic syndrome in adolescents and young adults with intellectual disabilities. Res Dev Disabil. 2014;35(11):2987-92. https://doi. org/10.1016/j.ridd.2014.07.050.

18. Fedewa MV, Russell AR, Nickerson BS, Fedewa MP, Myrick JW, Esco MR. Relative accuracy of body adiposity index and relative fat mass in participants with and without down syndrome. Eur J Clin Nutr. 2019;73(8):111721. https://doi.org/10.1038/s41430-018-0351-3.

19. Finlayson J, Morrison J, Jackson A, Mantry D, Cooper SA. Injuries, falls and accidents among adults with intellectual disabilities: prospective cohort study. J Intellect Disabil Res. 2010;54(11):966-80. https://doi.org/10.111 $1 / j .1365-2788.2010 .01319 . x$

20. Tolentino-Castro JW, Mühlbeier A, Mochizuki L, Wagner H. Delayed latency of postural muscles of individuals with intellectual disabilities. Front Psychol. 2018;9:109. https://doi.org/10.3389/fpsyg.2018.00109.
21. Dupre C, Weidman-Evans E. Musculoskeletal development in patients with down syndrome. JAAPA. 2017;30(12):38-40. https://doi. org/10.1097/01.JAA.0000526779.77230.79.

22. Budnik A. Prawa osób z niepełnosprawnością intelektualną w świetle europejskiego i polskiego ustawodawstwa. AE. 2017;14:103-26. https:// doi.org/10.26881/ae.2017.14.07.

23. World Health Organization. Obesity and overweight Fact sheet 2020. https://www.who.int/news-room/fact-sheets/detail/obesity-and-overw eight. Accessed 1 Jun 2020.

24. World Health Organization. Waist circumference and waist-hip ratio. Report of a WHO expert consultation, Geneva, 8-11 Dec 2008. https:// apps.who.int/iris/bitstream/handle/10665/44583/9789241501491_eng. pdf?ua=1 Accessed 1 Jun 2020.

25. Gawlik K, Zwierzchowska A, Celebańska D. Impact of physical activity on obesity and lipid profile of adults with intellectual disability. J Appl Res Intellect Disabil. 2018;31(2):308-11. https://doi.org/10.1111/jar.12406.

26. Parente EB. Is body mass index still a good tool for obesity evaluation? Arch Endocrinol Metab. 2016;60(6):507-9. https://doi.org/10.1590/23593997000000232.

27. Jabłonowska-Lietz B, Wrzosek M, Włodarczyk M, Nowicka G. New indexes of body fat distribution, visceral adiposity index, body adiposity index, waist-to-height ratio, and metabolic disturbances in the obese. Kardiol Pol. 2017;75(11):1185-91. https://doi.org/10.5603/KP.a2017.0149.

28. Bandini LG, Fleming RK, Scampini R, Gleason J, Must A. Is body mass index a useful measure of excess body fatness in adolescents and young adults with Down syndrome? J Intellect Disabil Res. 2013;57(11):1050-7. https://doi.org/10.1111/j.1365-2788.2012.01605.x.

29. Ramírez-Vélez R, Correa-Bautista JE, González-Ruíz K, Vivas A, García-Hermoso A, Triana-Reina HR. Predictive validity of the body adiposity index in overweight and obese adults using dual-energy $\mathrm{X}$-ray absorptiometry. Nutrients. 2016;8(12):737. https://doi.org/10.3390/nu8120737.

30. Cerqueira MS, Santos CAD, Silva DAS, Amorim PRDS, Marins JCB, Franceschini SDCC. Validity of the body adiposity index in predicting body fat in adults: a systematic review. Adv Nutr. 2018;9(5):617-24. https://doi. org/10.1093/advances/nmy043.

31. Geliebter A, Atalayer D, Flancbaum L, Gibson CD. Comparison of body adiposity index (BAl) and BMI with estimations of \% body fat in clinically severe obese women. Obesity (Silver Spring). 2013;21 (3):493-8. https:// doi.org/10.1002/oby.20264.

32. Nickerson BS, Esco MR, Bicard SC, Russell AR, Williford HN, Schaefer G. Validity of the body adiposity index in adults with Down syndrome. Res Dev Disabil. 2015;38:92-6. https://doi.org/10.1016/.j.ridd.2014.12.010.

33. Rossato M, Dellagrana RA, de Souza BE, da Costa RM, Dos Santos JOL, Silva DAS, et al. Comparison of body adiposity index (BAI) and air displacement plethysmograph with estimations of \% body fat in adults with Down's syndrome. Eur J Clin Nutr. 2017;71(11):1341-4. https://doi, org/10.1038/ejen.2017.1.

\section{Publisher's Note}

Springer Nature remains neutral with regard to jurisdictional claims in published maps and institutional affiliations.

Ready to submit your research? Choose BMC and benefit from

- fast, convenient online submission

- thorough peer review by experienced researchers in your field

- rapid publication on acceptance

- support for research data, including large and complex data types

- gold Open Access which fosters wider collaboration and increased citations

- maximum visibility for your research: over $100 \mathrm{M}$ website views per year

At BMC, research is always in progress.

Learn more biomedcentral.com/submissions 